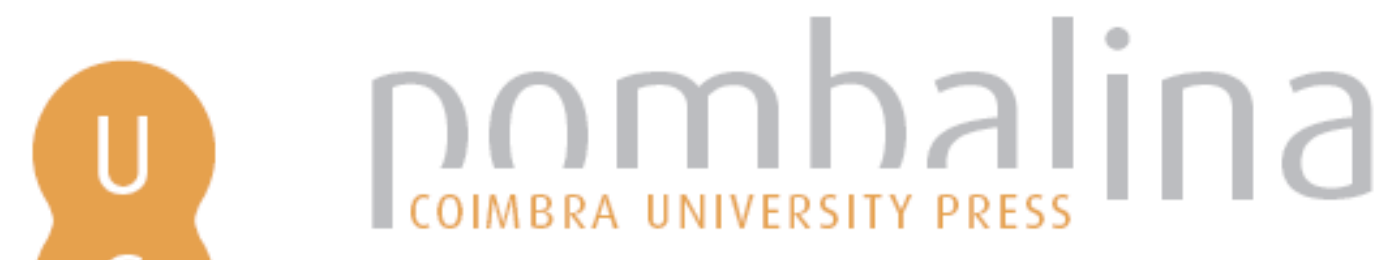

\title{
Adaptabilidade e orientação ao longo da vida
}

Autor(es): $\quad$ Silva, José Manuel Tomás da

Publicado por: Imprensa da Universidade de Coimbra

URL

persistente: URI:http://hdl.handle.net/10316.2/31237

DOI: $\quad$ DOI:http://dx.doi.org/10.14195/978-989-26-0228-8_6

Accessed : $\quad$ 26-Apr-2023 11:49:22

A navegação consulta e descarregamento dos títulos inseridos nas Bibliotecas Digitais UC Digitalis, UC Pombalina e UC Impactum, pressupõem a aceitação plena e sem reservas dos Termos e Condições de Uso destas Bibliotecas Digitais, disponíveis em https://digitalis.uc.pt/pt-pt/termos.

Conforme exposto nos referidos Termos e Condições de Uso, o descarregamento de títulos de acesso restrito requer uma licença válida de autorização devendo o utilizador aceder ao(s) documento(s) a partir de um endereço de IP da instituição detentora da supramencionada licença.

Ao utilizador é apenas permitido o descarregamento para uso pessoal, pelo que o emprego do(s) título(s) descarregado(s) para outro fim, designadamente comercial, carece de autorização do respetivo autor ou editor da obra.

Na medida em que todas as obras da UC Digitalis se encontram protegidas pelo Código do Direito de Autor e Direitos Conexos e demais legislação aplicável, toda a cópia, parcial ou total, deste documento, nos casos em que é legalmente admitida, deverá conter ou fazer-se acompanhar por este aviso. 


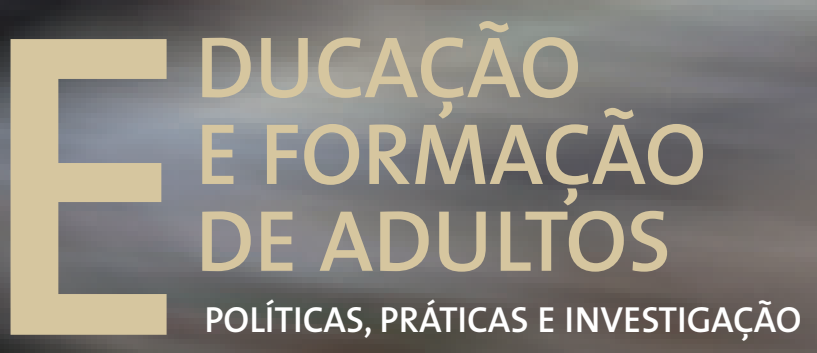

Luís Alcoforado • Joaquim Armando G. Ferreira António Gomes Ferreira • Margarida Pedroso de Lima Cristina Vieira • Albertina L. Oliveira • Sónia Mairos Ferreira 


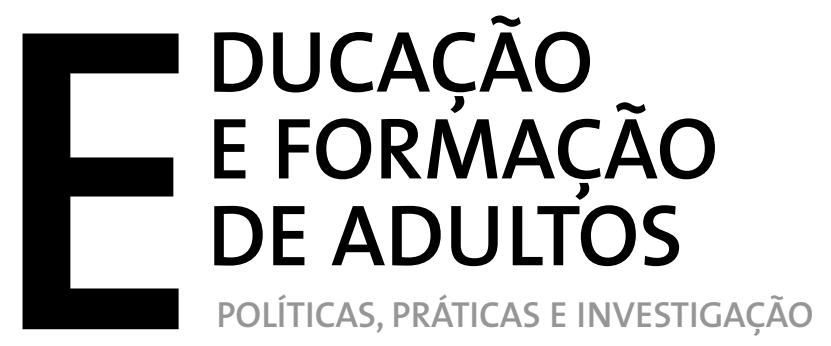

Luís Alcoforado • Joaquim Armando G. Ferreira António Gomes Ferreira - Margarida Pedroso de Lima Cristina Vieira • Albertina L. Oliveira • Sónia Mairos Ferreira 
EDIÇÃo

Imprensa da Universidade de Coimbra

URL: http://www.uc.pt/imprensa_uc

Vendas online: http://www.livrariadaimprensa.com

CONCEPÇÃO GRÁFICA

António Barros

Pré-Impressáo

SerSilito-Empresa Gráfica, Lda

EXECUÇÃo GRÁFICA

SerSilito-Empresa Gráfica, Lda

ISBN

978-989-26-0136-6

DePósito LEgaL

$340309 / 12$ 



\title{
Adaptabilidade E ORIENTAÇÁo AO LONGO DA VIDA
}

\author{
José Manuel Tomás da Silva \\ Universidade de Coimbra
}

Neste capítulo aborda-se a questão suscitada pela emergência da sociedade pós-industrial e procura-se aclarar qual o seu impacto no mundo do trabalho e na estrutura e evoluçáo das carreiras profissionais. Entre os autores actuais da ciência da carreira há uma consciência generalizada de que as mudanças são mais rápidas, frequentes, não-lineares e imprevisíveis do que no passado e que estas novas características transformacionais acarretam profundas alteraçóes no modo de funcionamento da sociedade e dos indivíduos que as compóem. $\mathrm{O}$ presente capítulo examina estas questóes em três partes fundamentais. Na primeira parte argumenta-se que o fenómeno da globalização e os avanços tecnológicos (especialmente, os que têm lugar no campo das tecnologias da informação) são os motores que propulsionam as mudanças dramáticas que, nas últimas três décadas, se verificaram no mundo do trabalho. A segunda parte apresenta as principais implicaçóes decorrentes das mudanças no mundo do trabalho na transformação das trajectórias de carreira tradicionais, tipicamente burocráticas, lineares e previsíveis, nos percursos profissionais mais caóticos, incertos e flexíveis da actualidade. A terceira parte sugere que, face aos crescentes desafios da nova realidade da carreira, é imperativo que os indivíduos aprendam a responder construtivamente a estas mudanças, ou seja, que mostrem maior adaptabilidade de carreira. Defende-se, por fim, que os profissionais de orientação de carreira poderão contribuir significativamente, com os seus conhecimentos e competências, para potenciar a capacidade de adaptação à mudança dos indivíduos.

Em suma, neste capítulo defendemos a tese de que a adaptabilidade de carreira é um conceito chave para a tecedura da orientação (de carreira) ao longo da vida (OLV) e uma meta-competência imprescindível para o sucesso no mundo do trabalho do século XXI.

\section{Mudanças no mundo do trabalho}

Como afirmaram Arnold e Jackson (1997) num simpósio denominado Perspectivas sobre a nova carreira, "dizer que o trabalho está a mudar é meramente um truísmo, pois isso foi sempre assim" (p. 427).

O nosso principal poeta, Luís de Camóes (c. 1524 - 1580), vários séculos antes destes autores, já tinha comentado esta ideia da "constância" da mudança, numa das suas líricas mais conhecidas: "Mudam-se os tempos, mudam-se as vontades/Muda-se o ser, muda-se a confiança/Todo o mundo é composto de mudança/Tomando sempre novas qualidades."

Afinal, podemos questionar, qual é o sentido especial que queremos sublinhar quando elegemos a mudança como a ideia-chave para compreendermos o novo mundo do trabalho e as carreiras que nele são construídas? O que há de radicalmente diferente nas sociedades desenvolvidas pós-1970?

Basicamente, no final da década de 70 e no início dos anos 1980 do século passado, o mundo ocidental iniciou uma viragem paradigmática entrando definitivamente na sociedade 
do conhecimento. Segundo Drucker (1993) "na sociedade do conhecimento o emblema da sociedade ou, se quisermos, o seu símbolo ou porta-bandeira, é a pessoa instruída (...) se o cavaleiro feudal foi a representação mais acurada da sociedade na Idade Média, e os "burgueses" o seu símbolo sob o capitalismo, a pessoa instruída representará a sociedade na era pós-capitalista na qual o conhecimento se tornou o recurso central” (p. 211).

$\mathrm{Na}$ passagem da sociedade industrial para a sociedade do conhecimento ocorreram mudanças profundas (e.g., Arnold \& Jackson, 1997; Oliveira, 2006; Wijers \& Meijers, 1996). Estas mudanças, na opinião de vários estudiosos, afectaram todos os aspectos relativos ao modo como o trabalho se vinha estruturando e organizando.

Castells (1999), por exemplo, descreve o aparecimento da sociedade "em rede", baseada na nova "matéria-prima" do informacionalismo e discute detalhadamente como esta "conectividade" global emergente e sem precedentes reestruturou o modo tradicional de produção capitalista.

Quando se trata de identificar as causas das transformaçóes em curso, os autores mostram um pensamento convergente: os dois motores principais das mudanças em curso são, respectivamente, a inovação tecnológica e a globalização. Para além dos factores propulsionadores da Tecnologia, sobretudo, das Tecnologias da Informação e da Comunicação (TIC), e da Globalização, por vezes discute-se ainda um terceiro factor respeitante às mudanças demográficas no mercado de trabalho (e.g., uma força de trabalho mais envelhecida, mais feminina e mais étnica e culturalmente diversa); mas os dois primeiros factores são inequivocamente os mais importantes.

Como sublinharam Karoly e Panis (2004) num relatório preparado para o Departamento do Trabalho (DOL) dos EUA, o progresso tecnológico, especialmente, nas tecnologias da informação [TI], na biotecnologia e na nanotecnologia [o estudo de manipulação da matéria numa escala atómica e molecular] continuarão a remodelar os processos de produção e os conteúdos das tarefas nos empregos e a forma como será disponibilizada a educação e a formação profissional relacionada com o trabalho. Acrescentam que muito previsivelmente essas tecnologias exigiráo - e recompensarão - uma força de trabalho altamente proficiente, mas que crescentemente estará menos dependente de uma localização particular [espaço físico] para a realização do trabalho necessário.

É inegável que os avanços nas TI contribuíram para a crescente globalização das economias, das empresas, dos negócios e das pessoas. As empresas cada vez mais competem num mercado internacional à escala planetária, o que supostamente deveria gerar mais benefícios para a população dos países de origem dessas corporaçóes, bem como para as sociedades de acolhimento. Mas, infelizmente, como hoje é dramaticamente perceptível para muitos observadores atentos (e.g., Rachman, 2011), o processo de globalização não está a gerar os efeitos positivos esperados e, pelo contrário, a cada dia que passa constatamos que esta dinâmica económica inexorável (e selvagem) está acontribuir para o aparecimento de mais vencidos do que vencedores, em resultado de uma economia mais aberta e desregulada (Karoly \& Panis, 2004).

Mais importante ainda para o futuro do trabalho é que as forças da TI e da globalização não actuam independentemente, mas têm efeitos interactivos relevantes. Atente-se, por exemplo, no papel das TI na promoção de uma maior integração económica entre as economias mundiais, à medida que os custos associados às comunicaçôes e à transmissão de dados vão caindo e as interacçóes de longa distância se vão tornando mais eficazes e operacionais. 
Ora, como refere Watts (1996), "a mudança tecnológica transforma continuamente a natureza da organização do trabalho; [enquanto] a competição global coloca uma pressão intensa sob organizaçáo para reduzir os custos, inovar e adaptar” (p. 3).

De facto, o pós-industrialismo, como afirma Gothard (2001), "caracteriza-se, em primeiro lugar, por uma ênfase na geração de informação como fonte principal da produtividade, em segundo lugar na mudança da produção de bens de consumo para a prestação de serviços, e finalmente pelo rápido crescimento das ocupaçóes gestionárias, profissionais e técnicas, com crescente polarizaçáo na estrutura ocupacional" (p. 2). O resultado destes desenvolvimentos é uma modificação radical do trabalho, do emprego e das carreiras.

\section{Mutaçóes nas carreiras}

Anthony Watts, em 1996, num documento intitulado Careerquake: Policy supports for self-managed careers, argumentou que estamos a viver uma transformação histórica, abrupta e inexorável, na direcção de uma nova era da informação pós-moderna e pós-industrial. Reconhece ainda que há, cada vez mais, uma maior consciencialização de que estas mudanças terão como provável consequência uma profunda revoluçáo, quer na natureza, quer nas estruturas, tanto do trabalho como das carreiras. O conceito de careerquake (ver Collins \& Watts, 1996) pretende transmitir, metaforicamente, a ideia de que um abalo sísmico socioeconómico e sociopolítico fez ruir as fundaçóes das concepçóes tradicionais sobre o trabalho, a educação/formação e a carreira, e, simultaneamente, procura transmitir a noção de que para evoluirmos deste estado negativo indesejável é necessário mudarmos de paradigma.

As consequências para a construção das novas carreiras são profundas e generalizadas e, conforme a perspectiva em que se coloque o observador, podem ser interpretadas, quer como ameaças, quer como oportunidades ou desafios. De qualquer modo, parece-nos inegável que para um significativo número de actores que integram a força de trabalho actual, o ritmo acelerado das mudanças e o carácter de imprevisibilidade que se lhes associa, causaram uma onda de choque cujos efeitos ainda não foram totalmente absorvidos.

\subsection{Características das novas carreiras}

Tim Hall (1976) foi um observador privilegiado do tsunami que se abateu sobre a carreira, especialmente, sobre as carreiras nas organizaçóes burocráticas tradicionais (por exemplo, em corporaçóes como a IBM, a General Electrics, etc.) e, bem cedo, procurou delinear as principais características que permitem distinguir a carreira tradicional das formas emergentes - as carreiras ditas "proteanas", ou multiformes (Hall, 2004; Hall \& Mirvis, 1996). Outros autores como, por exemplo, Arthur (1994) e Pryor e Bright (2003), também contribuíram para a renovação do léxico das carreiras pós-"careerquake" introduzindo, respectivamente, as expressóes de "carreiras sem fronteiras" (boundaryless careers) e de carreiras não-lineares.

As carreiras "proteanas" - assim designadas por referência a Proteu, o Deus do mar da mitologia grega que metamorfoseando-se, assume a aparência que deseja - são principalmente dirigidas pelas pessoas e não pelas empresas que as empregam. As pessoas com este tipo 
de carreiras orientam-se por valores fundamentais como a liberdade e o desenvolvimento pessoal e, segundo Hall (2004), revelam um elevado grau de mobilidade (sobretudo no plano interorganizacional). O grau de sucesso na carreira é construído subjectivamente (sucesso psicológico) e as atitudes-chave para a aferição do êxito são a satisfação no trabalho e o comprometimento profissional (reputação).

Esta descrição contrasta drasticamente com a imagem tradicional da carreira descrita no livro The Organization Man (sic.) de William H. Whyte. Whyte escreveu em 1956 este bestseller com base num conjunto de entrevistas com os CEOs de corporaçóes como a General Electric e a Ford. Segundo Hall (e.g., 1976, 2004), o locus da carreira tradicional (a forma dominante até aos anos 1980) está na organização e não na pessoa. É a entidade empregadora que gere a carreira da pessoa. Depois de entrar numa organizaçấo, a pessoa seguia por um caminho pré-estabelecido (carreira, etimologicamente, provém do vocábulo Francês Medieval carriere "estrada, pista de corrida" e do latim (via)cararia: estrada/via para carros), estando o progresso nesse percurso principalmente condicionado, para iguais níveis de aptidão e de motivação, pela experiência profissional adquirida (ou, senioridade na organização). Donde não ser surpresa que o valor profissional mais referido pelas pessoas durante o século vinte fosse o avanço na carreira. O sucesso, por isso, aferia-se através do nível salarial auferido o qual, em geral, estava correlacionado com a progressão nos escalóes e nas categorias previstas na carreira. Atendendo à importância da senioridade numa organização para o avanço na carreira, a mobilidade interorganizaçóes era necessariamente reduzida. Para alguém nascido nos anos de 1920 o padrão de carreira normativo caracterizar-se-ia em entrar numa organização e nela permanecer até ao momento da reforma. Obviamente, hoje em dia este padrão só é observado numa percentagem minoritária de trabalhadores e, desde há muito tempo que já não constitui a norma para as pessoas inseridas no mercado de trabalho. Contrastando com a atitude de comprometimento com a profissão das novas carreiras, a atitude dominante na carreira tradicional era do comprometimento com a organizaçáo (Hall, 1976).

\subsection{Linhas de desenvolvimento das novas carreiras}

A evolução das carreiras tradicionais para as carreiras multiformes da pós-modernidade náo aconteceu abruptamente; aliás os factores que influíram no seu desenvolvimento ainda permanecem activos e continuam a fazer sentir os seus efeitos nos nossos dias. Donde, ser algo exagerado, e empiricamente errado, admitir-se categoricamente, como sugere o título da obra de Hall e associados (1996), que "a carreira está morta."

No esquema proposto por Handy (1989), para a estrutura típica das organizações do século XXI - a estrutura em forma de trevo de três folhas (organização shamrock) - continuamos a discernir um componente que agrega o conjunto de empregados nucleares (core) da organização, a par com os outros dois componentes (significativamente mais numerosos) dos trabalhadores subcontratados e dos trabalhadores temporários e dos que desempenham funçóes a tempo parcial. As carreiras clássicas de tipo burocrático, estreitamente identificadas com o grupo de trabalhadores core da organização, perduram e prosperam na actual organização do trabalho e continuam a usufruir de contratos psicológicos relacionais (e.g., Rousseau, 1995), que lhes garantem um vasto conjunto de prerrogativas e benefícios, designadamente: segurança no emprego, prémios e gratificaçóes suplementares, e promoçóes em troco de lealdade demonstrada para com a empresa e de um nível de produtividade adequado. 
Os trabalhadores a tempo parcial e os que desempenham funçóes temporárias, por sua vez, estariam abrangidos por contratos transaccionais, ou seja, uma forma de contrato psicológico em que os empregados já não esperam (ou deixaram de poder esperar) uma relação duradoura com a organizaçáo que lhes dá emprego. Os contratos transaccionais não dão garantias de segurança no emprego, apenas asseguram a possibilidade de empregabilidade. Assim, em troca de longas horas de trabalho e de um empenho extra os trabalhadores deveriam poder esperar um salário mais elevado e maior apoio para a obtenção de formação profissional e de acesso a actividades de desenvolvimento pessoal. Infelizmente o equilíbrio desejado entre estes dois objectivos, de certo modo antagónicos (menor segurança no emprego em troca de uma maior empregabilidade, via formaçáo profissional e desenvolvimento de novas competências), como sabemos, não se tem materializado, salvo raras excepçóes. $\mathrm{Na}$ verdade, em muitos casos os empregadores náo podem (ou náo querem), cumprir a sua parte do contrato e alienam essa responsabilidade para o trabalhador. Por essa razáo vemos na literatura especializada cada vez mais referido o conceito de que a carreira profissional não pertence à organização, mas ao indivíduo (Duarte, 2009). A noção de empregabilidade (vs. emprego para a vida) adquiriu uma notoriedade incontornável no discurso contemporâneo sobre a nova "realidade" do trabalho. $\mathrm{Na}$ actualidade manter-se reempregável é um capital altamente desejável para qualquer trabalhador, mas sobretudo para o numeroso grupo dos que apenas têm trabalho temporário ou a tempo parcial.

Vários estudos prospectivos estimam que os indivíduos que entram no mercado de trabalho tenderão a experimentar uma série de papéis de trabalho. As previsóes sugerem que estes trabalhadores irão ter entre 12 a 25 postos de trabalho, em vários sectores do mercado de trabalho, ao longo da sua vida profissional. Em certos momentos da sua vida profissional estes indivíduos podem ter dois ou mais empregos simultâneos a tempo parcial, enquanto em outras fases não terão qualquer tipo de trabalho remunerado (Jarvis, 2003).

A economia do conhecimento está a mudar o modo como as pessoas trabalham (Alcoforado, 2001; Jackson, Arnold, Nicholson \& Watts, 1996) e, cada vez com mais frequência, encontraremos pessoas com padróes de carreira em que os períodos de trabalho serão intercalados com períodos de aprendizagem/formação, podendo estes ser a tempo integral (sabáticas profissionais) ou parcial.

No mundo pós-industrial actual, como diz Watts (1996), uma sociedade que deseja dispor de empregos de elevada qualidade, tem que ser necessariamente uma sociedade de aprendizagem. Donde, emprego e educação são processos que não devem ser vistos isoladamente: aprende-se para trabalhar, trabalha-se para aprender.

Como corolário do que até agora foi dito, é legítimo afirmar-se que as necessidades contínuas e persistentes de desenvolvimento e de aprendizagem ao longo da vida, características dos nossos dias, exigem uma orientação vocacional que seja também ela contínua (do "berço à tumba"), ou seja, uma orientação ao longo da vida (OLV): uma actividade sistemática de ajuda que se (pre)ocupe, entre outras coisas, com a promoção da empregabilidade das pessoas.

Há uma miríade de factores que hipoteticamente influenciam a capacidade das pessoas para ao longo da vida manifestarem o atributo de empregabilidade (e.g., Fugate, Kinicki \& Ashforth, 2004). Na terceira parte deste texto iremos centrar-nos apenas numa das características pessoais que a literatura científica sobre a carreira, consistentemente, aponta como tendo um papel importante para o sucesso na carreira, isto é, o conceito de adaptabilidade na carreira (Hall, 2002; Savickas, 1997). 


\section{Adapabilidade de carreira: definiçâo, avaliaçáo e promoçáo}

O conceito de adaptabilidade é discutido em alguns dos modelos teóricos da carreira mais influentes na actualidade, quer no domínio da Psicologia Vocacional (e.g., Savickas, 1997, 2005), quer no campo da Psicologia das Organizaçóes (e.g., Morrison \& Hall, 2002).

Num dos textos fundamentais sobre esta matéria, Mark Savickas (1997) mostra que o conceito de adaptação é basicamente um legado da escola funcionalista. Esta escola de pensamento esforçou-se por encontrar respostas não triviais para duas questóes principais: "O que é que as pessoas fazem?" e "Porque é que o fazem?" As respostas a ambas as perguntas, do ponto de vista funcionalista, são respectivamente: as pessoas "adaptam-se" e "fazem-no no pressuposto de alcançarem um bom ajustamento do seu auto-conceito às suas situaçóes de vida” (Savickas, 1997, p. 253).

\subsection{Definição e natureza do construto de adaptabilidade de carreira}

De acordo com Savickas (1997) a raiz da palavra adaptação é apto, que significa rápido a aprender ou a compreender. Por sua vez, a origem do verbo adaptar remonta ao latim e à palavra Francesa, ad aptar, que significa "caber/ajustar." Esta ideia de ajustamento permanece ainda hoje central na ciência da carreira (e.g., congruência), nomeadamente nas teorias de ajustamento pessoa-ambiente. Savickas (1997), mergulhando mais fundo na exegese hermenêutica, sugere que a palavra adaptação significa tornar-se mais adequado, ou congruente, através da mudança. Adicionalmente, o termo suscita a ideia de flexibilidade na resposta ao ambiente, num sublinhado teleológico que informa, simultaneamente, sobre intenção da mudança (o seu para quê?). Finalmente, a palavra adaptação póe o acento tónico na interacção entre o indivíduo e o ambiente.

Para Morrison e Hall (2002), adaptabilidade é uma qualidade de ordem superior, ou uma metacompetência, essencial para a eficácia na carreira. Os autores contrastam a adaptabilidade com a identidade (outra metacompetência do seu modelo), mencionando que esta última diz respeito primariamente à pessoa enquanto a primeira tem mais a ver com a tarefa (e as mudanças que ocorrem a esse nível). Ambos os autores reconhecem, todavia, que esta distinçâo não é totalmente clara, uma vez que as pessoas aprendem acerca de si mesmas (identidade) através do sucesso que alcançam nas tarefas com que se deparam, enquanto ao mesmo tempo aumentam as competências nas tarefas mudando-se a si mesmos e mudando o modo como lidam com as tarefas. Assim, a adaptabilidade para Morrison e Hall (2002), "é a capacidade para se adaptar e mudar" (p. 205).

Subjacente à maior parte das propostas teóricas acerca da adaptabilidade está a ideia de que os indivíduos desenvolvem imensos esforços com vista a adaptar-se e a aceitar a mudança. Como vimos anteriormente, a mudança é uma constante do dia-a-dia das sociedades pós-industriais. Neste ambiente turbulento, as pessoas têm de lidar com muito mais transiçôes e precisam de ser, simultaneamente, mais adaptáveis e competentes a aprender (Hall \& Chandler, 2005).

Donald Super foi quem pela primeira propôs o construto de adaptabilidade de carreira (e.g., Super \& Knasel, 1981), considerando-o indispensável para a compreensão do desenvolvimento vocacional dos adultos e ulteriormente uma ferramenta analítica de grande utilidade para ajudar os indivíduos a enfrentar a nova realidade mercado de trabalho característica da era pós-industrial. 
O conceito de adaptabilidade propunha-se substituir o de maturidade vocacional/ carreira, proposto por Super e colaboradores nos anos 1950 do século XX, para explicar o processo de desenvolvimento vocacional dos jovens/adolescentes (vide Silva [2004] para uma resenha histórica sobre estes conceitos). Super e Knasel (1981) argumentaram que o comportamento vocacional dos adultos difere radicalmente do comportamento dos adolescentes, uma vez que o adulto, por norma, tem um maior envolvimento e experiência com o mundo do trabalho, enquanto para o adolescente a experiência de trabalho é, em geral, fragmentária, incipiente e amplamente antecipatória. Assim, se para o grupo dos jovens o conceito de maturidade ainda pode ter alguma utilidade, isso já não se verificaria no caso dos adultos, onde a aplicação do conceito se reveste de séries dificuldades, designadamente as que decorrem de juízos valorativos sobre o grau de maturidade/imaturidade de certos comportamentos com relevância vocacional (por exemplo, um adulto em transição é menos "maduro" vocacionalmente do que outro que permaneceu no mesmo emprego?).

O conceito de adaptabilidade de carreira procurou capturar, no sentido que the imprimiram Super e Knasel, o "equilíbrio que cada indivíduo procura entre o mundo do trabalho e o seu ambiente pessoal (...). Uma das principais razóes para a introdução do termo 'adaptabilidade de carreira' é que ele possibilita que uma maior ênfase seja dada aos novos problemas, não necessariamente de tipo maturativo, com que presentemente se confrontam a maioria das pessoas" (Super \& Knasel, 1981, p. 199).

Para Savickas (2005), um discípulo e continuador de Super, adaptabilidade de carreira, um componente central da Teoria da Construção de Carreira (TCC), diz respeito às "atitudes, competências e comportamentos que os indivíduos usam para se adaptarem ao trabalho que mais lhes convém” (p. 45).

Mais formalmente, definiu adaptabilidade de carreira como "um construto psicossocial que denota a preparação de um indivíduo e os recursos [de que dispóe] para lidar com as tarefas de desenvolvimento vocacional actuais e as antecipadas" (Savickas, 2005, p. 45).

Convém precisar que a adaptabilidade de carreira não é um construto psicológico exclusivamente intrapsíquico como são, por exemplo, os tipos de personalidade RIASEC de Holland (1997); antes constitui um construto psicossocial, ou seja, um processo que traduz o resultado da relação recíproca e contínua entre as características relevantes da pessoa (e.g., ABC's da carreira, descritos adiante) e as tarefas de desenvolvimento estabelecidas pela sociedade onde esta se insere. Como sublinha Savickas (2005), "a adaptabilidade representa o alargamento do self (eu) aos ambientes sociais à medida que os indivíduos entram em contacto com a sociedade e regulam o seu próprio comportamento vocacional face às tarefas de desenvolvimento vocacional impostas pela comunidade e às transiçóes ocupacionais encontradas em diferentes papéis sociais (p. 51).

No trabalho que vimos seguindo de perto, Savickas delineou as dimensóes globais da adaptabilidade de carreira, tomando por base o trabalho pioneiro de Super e Knasel (1981) quando procuraram adequar o conceito de maturidade de carreira às vivências e circunstâncias dos adultos.

O modelo estrutural da adaptabilidade da carreira (e.g., Savickas, 2005, p. 53) inclui três diferentes níveis ou estratos. No nível mais alto e abstracto o modelo contempla as quatro dimensóes da adaptabilidade de carreira - os 4C's (primeira letra da palavra usada em língua inglesa) - cada uma denominada de acordo com a sua função principal: preocupação (Concern), controlo (Control), curiosidade (Curiosity), confiança (Confidence). Estas quatro dimensóes representam as estratégias e os recursos adaptativos gerais que os 
indivíduos usam para gerir tarefas críticas, transiçóes e traumas (e.g., episódio de desemprego) à medida que constroem as suas carreiras.

No nível seguinte - nível intermédio - o modelo articula um conjunto distinto de variáveis funcionais homogéneas para cada uma das quatro dimensóes globais. Cada um destes conjuntos de variáveis intermédias inclui as atitudes, crenças e competências específicas - os ABC's (Attitudes, Beliefs, Competencies) da construçâo de carreira - que modelam os comportamentos que os indivíduos usam para lidar com as tarefas de desenvolvimento, negociar as transiçóes de carreira, e resolver os traumas pessoais.

As competências cognitivas - retratadas no terceiro nível e também o mais concreto de todos os identificados no modelo - por sua vez, moldam o comportamento vocacional propriamente dito. Os comportamentos vocacionais, por fim, designam as numerosas respostas de confronto que os indivíduos usam para produzir e construir as suas carreiras.

As dimensôes adaptativas principais são respostas a questôes de carreira específicas. Assim, por exemplo, a pergunta "Terei um futuro?" diz respeito à dimensão "preocupação"; "Quem é o dono do meu futuro?" corresponde à dimensão de controlo; à pergunta "O que quero fazer com o meu futuro?” associa-se a dimensão curiosidade; finalmente, à questão "Posso fazê-lo?" está associada à dimensão de confiança pessoal.

Como é que o indivíduo revela ter competência adaptativa? Segundo Savickas (1997, 2005), uma pessoa denota adaptabilidade de carreira (1) mostrando-se genuinamente preocupado com o seu futuro como trabalhador, (2) aumentando o grau de controlo pessoal sobre o seu futuro profissional, (3) exibindo curiosidade e explorando "eus" possíveis e cenários futuros, e (4) adquirindo e fortalecendo a confiança necessária para alcançar e concretizar as suas aspirações de carreira.

\subsection{Avaliação da adaptabilidade de carreira}

O processo geral de avaliação de carreira "envolve a recolha de evidências sobre os indivíduos, a fim de ajudá-los a gerir suas carreiras” (Kidd, 2006). Avaliar o grau de adaptabilidade de carreira de um modo credível significa que os procedimentos ou dispositivos de medida que construirmos para recolher evidências sobre esse atributo têm de possuir características de precisão e de validade, isto é, têm de avaliar consistentemente o construto e apenas o construto que se propóem medir. Avaliar o desenvolvimento vocacional dos adultos, como referem diversos autores, não tem sido uma tarefa fácil. No grupo dos adolescentes a tarefa de avaliação, embora longe de ser um processo simples, encontra-se facilitada, pois, neste caso os problemas e os objectivos da avaliaçáo tipicamente concentram-se em torno da tomada de decisão de carreira, já que a maioria deles geralmente quer obter ajuda para a realização de uma escolha de carreira.

Já com os adultos a situação de avaliação é mais complexa, raramente se circunscrevendo exclusivamente aos problemas de decisão de carreira. Os adultos confrontam-se com um conjunto heterogéneo de problemas ao procurarem adaptar-se às mudanças no trabalho e às condiçóes de trabalho. Donde, frequentemente, requererem ajuda para outro tipo de dificuldades, designadamente para aquelas que se encontram relacionadas com a adaptação/ajustamento à carreira (remetendo para tópicos/dilemas que se prendem, por exemplo, com o sucesso e a satisfação na carreira). Esta heterogeneidade de problemas de carreira tem constituído um sério obstáculo à construção de medidas de adaptabilidade. 
Ao construírem estas medidas, os investigadores decidiram começar por identificar os problemas mais frequentemente experienciados pelos adultos em diferentes fases da carreira.

A primeira medida da adaptabilidade alguma vez construída a Adult Career Concerns Inventory (ACCI: Super et al., 1988), concentrava-se apenas na identificação dos problemas (preocupaçóes) dos respondentes. As medidas que foram desenvolvidas subsequentemente, tais como o Career Mastery Inventory (CMI: Crites, 1990) e o Occupational Stress Inventory (OSI: Osipow \& Spokane, 1987), procuraram simultaneamente identificar os problemas de carreira e avaliar os reportórios de confronto dos indivíduos. O OSI, por exemplo, foi construído para medir a adaptaçáo ao stress experienciado no papel de trabalho, no pressuposto de que o elevado stress ocupacional terá um impacto negativo no grau de ajustamento da pessoa ao posto de trabalho ou irá exacerbar um desajustamento pré-existente. O OSI inclui três escalas de stress: Occupational Roles Questionnaire (ORQ: mede a sobrecarga de tarefas, ambiguidade, etc.); Personal Strain Questionnaire (PSQ: avalia atensão psicológica resultante do stress (strain), contemplando, por exemplo, problemas intrapessoais como depressão, ansiedade, irritabilidade); Personal Resources Questionnaire (PRQ: avalia os recursos de confronto disponíveis, designadamente a Escala Recreativa mede a extensão em que os respondentes usam o descanso, o relaxamento e actividades recreativas para reparar os estragos causados pelo stress ocupacional). Infelizmente todas estas medidas têm sido pouco usadas pelos profissionais de orientação e, na verdade, não avaliam muitas das preocupaçôes contempladas no modelo de adaptabilidade de carreira de Savickas (1997, 2005) que expusemos acima.

Face às dificuldades referidas, muitos profissionais de Orientação de Carreira preferem usar métodos de avaliação mais informais ou qualitativos. Vários exemplos podem ser mencionados nesta categoria, os seguintes sendo os mais tipicamente usados: entrevistas semi-estruturadas, métodos autobiográficos, memórias precoces (early recollections), card sorts.

A Career Style Interview (CSI: Savickas, 2011), por exemplo, é uma entrevista estruturada que facilita a identificação de temas de vida e consiste na formulação de uma curta lista de perguntas aos clientes acerca das suas experiências vocacionais e educacionais. Mais concretamente, a CSI usa oito questōes (e.g., Modelos, Livros, Revistas, Actividades de Lazer, Matérias escolares, Lemas, Ambiçôes, Decisôes) para extrair a perspectiva subjectiva de um cliente sobre escolha e adaptação à carreira. Um bom exemplo do uso das técnicas qualitativas na avaliação da adaptabilidade de carreira pode ver-se no trabalho de Ebberwein, Krieshok, Ulven e Prosser (2004).

$\mathrm{Na}$ última década do século passado a avaliação da adaptabilidade entrou numa situação de impasse. Por um lado, os instrumentos quantitativos não possuíam suficiente validade de conteúdo (as dimensóes importantes do construto não estavam contempladas nesses procedimentos) e as técnicas qualitativas, por sua vez, apesar da riqueza clínica das observaçóes que conseguem gerar são difíceis de usar em aplicaçóes colectivas.

Os investigadores da carreira durante a última década procuraram ultrapassar as limitaçôes apontadas acima, criando baterias de medidas adaptadas às dimensôes do construto de adaptabilidade de carreira. Estas baterias compósitas têm vindo a ser usadas principalmente na investigaçáo, mas podem ser igualmente usadas no aconselhamento de carreira. $\mathrm{Na}$ literatura encontramos uma grande diversidade de variáveis que foram propostas como marcadores das dimensôes da adaptabilidade de carreira. As que apresentamos de seguida foram seleccionadas porque foram usadas em pelo menos dois estudos independentes como indicadores dos 4C's do modelo estrutural de Savickas (1997, 2005). 
Creed, Fallon e Hood (2009) estudaram o papel mediador da adaptabilidade de carreira nas relaçóes entre variáveis pessoais (orientação para objectivos) e situacionais (suporte social) e as preocupaçóes de carreira de jovens adultos. O construto de adaptabilidade de carreira foi operacionalizado através de uma bateria de indicadores liberalmente baseado no modelo de Savickas, composto por variáveis de planeamento de carreira, exploração do eu e da carreira, de tomada de decisão e de capacidade de auto-regulação.

Para estudarem o impacto da adaptabilidade de carreira nas estratégias de procura de emprego e na qualidade ulterior de reemprego, num grupo de adultos que no início do estudo recebiam subsídio de desemprego há mais de seis meses e estavam inscritos numa agência de reemprego Holandesa, Koen, Klehe, VanVianen, Zikic e Nauta (2010), usaram um conjunto de indicadores para avaliarem o construto de adaptabilidade, integrando variáveis de planeamento, exploração, tomada de decisão e grau de confiança pessoal.

Contudo nem todas as investigaçôes recentes se baseiam no modelo de Savickas (1997). McArdle, Waters, Briscoe e Hall (2007), por exemplo, estudaram empiricamente numa amostra de 416 desempregados australianos, o modelo de Fugate, Kinicki e Ashforth (2004) sobre o conceito de empregabilidade. Neste modelo a empregabilidade é definida como um construto psicossocial compreendendo três dimensóes: adaptabilidade, identidade de carreira e capital humano e social. Como indicadores do construto de adaptabilidade, McArdle et al (2007) usaram medidas de personalidade proactiva (exemplo de tipo de item: "Sou excelente a identificar oportunidades") e de atitude mental tipo "boundaryless" (exemplo de item: "Eu gosto de tipos de empregos que requerem que interaja com pessoas em muitas organizaçóes diferentes").

Os três estudos empíricos que referimos foram todos realizados com amostras de jovens adultos e adultos (e, em particular, com adultos desempregados). Este dado náo é propriamente uma surpresa, uma vez que a população de adultos é aquela que actualmente se vê confrontada com a necessidade de fazer face a múltiplas transições de vida e, como vimos na secção anterior, a adaptabilidade de carreira é um construto especialmente pertinente para a negociação eficaz dessas transiçóes. Mas é importante lembrar que, do ponto de vista teórico, o conceito de adaptabilidade é aplicável a todo o ciclo de vida da pessoa (Savickas, 1997). Inclusive, existe já alguma evidência empírica que suporta a generalização do construto de adaptabilidade à população dos adolescentes.

Andreas Hirschi (2009), por exemplo, num estudo longitudinal procurou determinar o papel de variáveis explanatórias baseadas na teoria dos sistemas motivacionais (e.g., disposiçóes emocionais positivas, crenças de capacidade) no desenvolvimento da adaptabilidade de carreira e no desenvolvimento ulterior do sentimento de poder pessoal e de satisfaçáo com a vida, numa amostra de 330 estudantes Suíços do $8^{\circ}$ ano. Baseando-se no modelo de Savickas (1997), a adaptabilidade de carreira foi avaliada através de quatro medidas: prontidão para a decisão de carreira, planeamento de carreira, exploração de carreira e confiança (crenças de auto-eficácia) de carreira.

É importante referir que todas as investigações referidas anteriormente operacionalizaram o construto de adaptabilidade de carreira juntando uma série de indicadores inicialmente construídos com finalidades de avaliação específicas (por exemplo, as medidas de exploração do eu e do ambiente que operacionalizam a faceta de exploração da adaptabilidade, são frequentemente extraídas do Career Exploration Survey, um instrumento desenvolvido por Stumpf, Colarelli e Hartman [1981] para avaliar as dimensóes do processo exploratório da carreira). 
O facto de distintos autores usarem medidas distintas das dimensôes da adaptabilidade suscita algumas dificuldades quando é preciso integrar os resultados dos diferentes estudos com o intuito de extrair conclusóes gerais sobre o papel do construto no comportamento vocacional. Há alguma esperança de que esta limitação possa ser corrigida no futuro próximo, pois um grupo de investigadores internacionais (e.g., Savickas et al., 2009) iniciou recentemente a tarefa de construir um instrumento transcultural da adaptabilidade de careira (para mais informação vide o número especial da Revista Portuguesa de Psicologia coordenado por Silva [2010/2011]).

Muito recentemente, Savickas e Porfeli (2011) relataram os resultados da revisão do Career Maturity Inventory (CMI) com a intenção de obterem uma Forma de Avaliação da Adaptabilidade (denominada Career Maturity Inventory - Counseling Form C) aplicável a adolescentes.

\subsection{Promoção da adaptabilidade de carreira}

Embora as medidas que referimos acima tenham, até ao momento, sido predominantemente utilizadas no âmbito da investigação, não há qualquer impedimento lógico para que não possam ser igualmente usadas de uma maneira mais clínica ou aplicada com o objectivo de promover a adaptabilidade de carreira (vide, por exemplo, Savickas \& Porfeli, 2011).

Apesar do estudo da adaptabilidade de carreira poder ser um fim importante em simesmo, acreditamos que o seu maior interesse reside na sua utilidade para informar o desenho de intervençôes de carreira eficazes visando a promoção e/ou desenvolvimento da capacidade de prontidão para a mudança, junto de adolescentes e adultos confrontados com múltiplas transiçóes de vida (Krumboltz \& Worthington, 1999). A intervenção de carreira, que podemos definir como "qualquer estratégia concebida para ajudar um cliente a tomar e a implementar decisóes eficazes de carreira” (Spokane \& Oliver, 1983), pode ser implementada para promover a adaptabilidade de carreira dos clientes através de uma vasta gama de estratégias desenvolvidas e melhoradas ao longo do século passado (Herr, 2011). Estas estratégias percorrem um largo espectro de actividades individuais e de grupo, com ou sem a participaçáo directa de um profissional, como, por exemplo, aconselhamento de carreira, orientaçáo de carreira, educaçáo para a carreira, colocaçáo ocupacional e coaching de carreira, entre muitas outras possíveis. Diversas meta-análises demonstraram que as intervençóes de carreira são tratamentos eficazes, embora a estimativa do tamanho do efeito varie conforme o estudo e a metodologia adoptada. Um estudo muito relevante neste âmbito revelou que quando alguns "ingredientes" estão presentes nas intervençóes de carreira a sua eficácia aumenta (Brown et al., 2003). Quais são esses "agentes activos"? Em primeiro lugar, os resultados deste estudo mostram que nas intervençóes eficazes os clientes são parte interessada e participam activamente no processo (frequentemente, realizando "trabalhos de casa" e completando tarefas entre as sessóes com o profissional de orientação). Em segundo lugar, os clientes recebem interpretaçóes e feedback personalizado da parte dos profissionais. A procura e a exploração de informação realizada no decurso da sessão de face-a-face com o profissional de orientação estão igualmente associadas a ganhos importantes na tomada de decisão. A utilização de princípios baseados na modelação de comportamentos é um quarto agente associado à eficácia dos tratamentos. Finalmente, Brown et al. (2003) constataram que nas intervençóes eficazes os clientes recebem durante 
o processo abundante suporte/apoio do profissional de orientação de carreira. Face a estes resultados, os profissionais de orientaçáo que querem ter um impacto na adaptabilidade de carreira dos clientes devem construir e/ou seleccionar estratégias de intervenção que integrem todos os ingredientes acima enunciados (ou, pelo menos, parte deles). Podemos, a título de exemplo, recomendar a utilização de estratégias educativas baseadas em métodos activos (e.g., a educaçáo para a carreira: Moreno, 2011); métodos de aprendizagem experiencial (e.g., job shadowing: Quirino, Paixão \& Silva, 2010); métodos narrativos (e.g., elaboração de um résumé construtivista: Scholl \& Cascone, 2010); utilização extensiva da Internet (como é ilustrado pelo sistema de orientação ao longo da vida implementado na Hungria, com recurso ao e-passaporte e ao e-portefólio: Watts \& Borbély-Pecze, 2010).

Todas as estratégias referidas partem do pressuposto de que a orientação de carreira no século XXI tem de assentar numa perspectiva de OLV, mais próxima do modelo de "higiene dental" (Goodman, 2004). Isto significa que os profissionais de orientaçáo devem estar disponíveis ao longo da vida para providenciar exames (checkups) de rotina sempre que as circunstâncias de vida das pessoas pressionem a sua adaptabilidade de carreira (e.g., no momento da implementação de uma primeira decisão de carreira; quando ocorrem mudanças no local de trabalho - possibilidade de promoçáo, transferência para novas funçóes, mudança de emprego, etc.). Nesta óptica de OLV, os serviços de carreira equivaleriam à consulta anual de estomatologia, onde vamos obter o certificado de que tudo está bem nesse âmbito; por outro lado, são necessárias actividades de manutenção regular (o equivalente à prática diária de escovar os dentes e usar o fio dental), o que no caso da carreira, pode consistir em manter o CV actualizado, conhecer as tácticas e técnicas de entrevista mais na "moda" ou, ainda, manter actualizada a rede de contactos profissionais). Apesar da ênfase que deve ser dada aos serviços de tipo promocional e desenvolvimentista, evidentemente que os profissionais devem continuar a oferecer serviços tradicionais (aconselhamento/ terapia) para situaçôes de crise e de emergência, despoletadas por acontecimentos de vida traumáticos (e.g., perda de emprego, acidentes de trabalho).

\section{Conclusáo}

Durante várias décadas o objectivo declarado das intervençóes de carreira foi o de ajudar os indivíduos a tomarem uma decisão de carreira (Herr, 2011; Savickas, 2000). No século XXI este objectivo pode ser uma receita para o desastre pessoal. As pessoas mudam e o seu ambiente altera-se constantemente. Hoje em dia, como procurámos mostrar ao longo deste capítulo, há uma consciência aguda de que não há empregos para a vida e que as carreiras, afinal não se escolhem e, pelo contrário, são construídas pelas pessoas através das interacçóes contínuas que estabelecem com o contexto socioeconómico característico da sociedade a que pertencem.

Assim, ao longo do texto desenvolvemos o argumento de que adaptabilidade de carreira é uma (meta) competência essencial para se ter êxito na Nova Economia, a qual, por enquanto, tem propiciado um generalizado "pandemónio" nas carreiras (Brousseau et al., 1996).

Adaptabilidade de carreira, no âmbito deste capítulo, foi definida como consistindo num conjunto de recursos psicológicos (atitudes, crenças e competências) que aprontam os indivíduos a lidar eficazmente com as permanentes mudanças nas suas vidas, especialmente 
(mas não exclusivamente) com as que sobrevêm no domínio do trabalho. Foram elencadas diversos procedimentos (quer qualitativos, quer quantitativos) que podem ser usados pelos profissionais de orientaçáo para avaliarem a adaptabilidade de carreira dos indivíduos e para orientarem na escolha de estratégias de intervenção individualizadas. Defendemos, ainda, que as intervenções de orientação de carreira no século XXI não podem mais estar exclusivamente circunscritas a um momento pontual do desenvolvimento humano (geralmente, o período que imediatamente precede a transição escola-mundo do trabalho), como foi sustentado por muitos estudiosos da carreira no passado. Na verdade, as mesmas razóes que conduziram à conclusão de que a aprendizagem deverá ser um processo ao longo da vida, são as que sustentam a ideia de que a Orientação de Carreira também terá de ser co-extensiva ao ciclo de vida dos indivíduos (Oliveira, 2006). Como referiu Jarvis (2003) "a economia do século vinte e um necessita de trabalhadores que sejam aprendizes ao longo da vida, que sejam capazes de responder e adaptar-se à mudança” (p. 2).

Pensamos que do ponto de vista político Portugal e os demais países da União Europeia precisam de continuar a apoiar activamente directrizes, como as que foram decididas no Conselho Europeu de 2008 (e.g., Council Resolutionon better integrating lifelong guidance into lifelong learning strategies, Bruxelas, 21 de Novembro) visando alargar e aprofundar as sinergias entre a Orientação ao Longo da Vida e a Aprendizagem ao Longo da Vida.

A Orientação da Carreira é um recurso fulcral para obter os objectivos sociopolíticos referidos, mas que tem sido sistematicamente ignorado (e mesmo desprezado) pelo poder político. É urgente mudar esta atitude. Estamos convictos que a Psicologia da Carreira e os profissionais de Orientaçáo estáo bem posicionados para promoverem essas importantes metas e dessa forma contribuírem, quer para o desenvolvimento mais equitativo e sustentável da sociedade, quer para a melhoria da satisfaçáo e do bem-estar dos cidadãos.

\section{Referências Bibliográficas}

Alcoforado, L. (2001). O modelo da competência e os adultos portugueses não qualificados. Revista Portuguesa de Pedagogia, 35, 67-83.

Arnold, J. \& Jackson, C. (1997). The New Career: Issues and Challenges. British Journal of Guidance and Counselling, 25, 427-433.

Arthur, M. B. (1994). The boundaryless career: A new perspective for organizational inquiry. Journal of Organizational Behavior, 15, 295-306.

Brousseau, K. R., Driver, M. J., Eneroth, K., e Larsson, R. (1996). Career pandemonium: Realigning organizations and individuals. Academy of Management Executive, 10, 52-66.

Brown, S. D., Ryan-Krane, N.E., Brecheisen, J., Castelino, P., Budisen, I., Miller, M., \& Edens. L. (2003). Critical ingredients of career choice interventions: More analyses and new hypotheses. Journal of Vocational Behavior, 62, 411-428.

Castells, M. (1999). The rise of the network society. Oxford: Blackwell.

Collins, A. \& Watts, A. G. (1996). The death and transfiguration of career - and of career guidance? British Journal of Guidance and Counselling, 24, 385-398.

Council Resolution on better integrating lifelong guidance into lifelong learning strategies. Acedido a 7/11/2011 em: $<$ http://www.consilium.europa.eu/ueDocs/cms_Data/docs/pressData/en/educ/104236.pdf..

Creed, P. A., Fallon, T., \& Hood, M. (2009). The relationship between career adaptability, person and situation variables, and career concerns in young adults. Journal of Vocational Behavior, 74, 219-229.

Crites, J. O. (1990). Career Mastery Inventory. Boulder, CO: Crites Career Consultants, Inc.

Drucker, P. F. (1993). Post-capitalist society. New York: Harper Publishing, Inc.

Duarte, M. E. (2009). The psychology of life construction. Journal of Vocational Behavior, 75, 259-266. 
Ebberwein, C. A., Krieshok, T. S., Ulven, J. C., \& Prosser, E. C. (2004). Voices in transition: Lessons on career adaptability. The Career Development Quarterly, 52, 292-308.

Fugate, M., Kinicki, A. J. \& Ashforth, B. E. (2004). Employability: A psycho-social construct, its dimensions, and applications. Journal of Vocational Behavior, 65, 14-38.

Goodman, J. (1994). Career adaptability in adults: A construct whose time has come. The Career Development Quarterly, 43, 74-84.

Gothard, B. (2001). Careers guidance in a new era. In B. Gothard, P. Mignot, M. Offer, \& M. Ruff (Eds.), Careers guidance in context (pp. 1-9). London: Sage.

Hall, D. T. (1976). Careers in organizations. Glenview, IL: Scott, Foresman.

Hall, D. T. \& Associates (1996). The career is dead-long live the career: A relational approach to careers. San Francisco: Jossey-Bass.

Hall, D. T. (2002). Careers in and out of organizations. Thousand Oaks, CA: Sage.

Hall, D. T. (2004). The protean career: A quarter-century journey. Journal of Vocational Behavior, 65, 1-13.

Hall, D. T. \& Chandler, D. E. (2005). Psychological success: When the career is a calling. Journal of Organizational Behavior, 26, 155-176.

Hall, D. T. \& Mirvis, P. H. (1996). The new protean career: Psychological success and the path with a heart. In D.T. Hall \& Associates, The Career is Dead - Long Live the Career, (pp. 15-45). San Francisco: Jossey-Bass Publishers.

Handy, C. (1989). The age of unreason. London: Business Brooks, Ltd.

Herr, E. L. (2011). Abordagens às intervençôes de carreira: Perspectiva histórica. In M. C. Taveira \& J. T. Silva (Eds.). Psicologia vocacional: Perspectivas para a intervenção (pp. 13-27). Coimbra: Imprensa da Universidade de Coimbra.

Hirschi, A. (2009). Career adaptability development in adolescence: Multiple predictors and effect on sense of power and life satisfaction. Journal of Vocational Behavior, 74, 145-155.

Holland, J. L. (1997). Making vocational choices (3rd ed.). Odessa, FL: Psychological Assessment Resources, Inc.

Jackson, C., Arnold, J., Nicholson, N., \& Watts, A. G. (1996). Managing careers in 2000 and beyond. IES Report 304. Brighton, IES.

Jarvis, P. S. (2003) Career Management Paradigm Shift. Prosperity for Citizens, Windfalls for Governments. Ottowa: National Life/Work Center.

Krumboltz, J. D. \& Worthington, R. L. (1999). The school-to-work transition from a learning theory perspective. The Career Development Quarterly, 47, 312-325.

Karoly, L. A. \& Panis, C. W. A (2004). The 21st century at work. Forces Shaping the Future Workforce and Workplace in the United States. Santa Monica, CA: RAND Corporation.

Kidd, J. M. (2006). Understanding career counselling. Theory, research and practice. London: Sage.

Koen, J., Klehe, U. C., Van Vianen, A. E. M, Zikic, J. \& Nauta, A. (2010). Job-search strategies and reemployment quality: The impact of career adaptability. Journal of Vocational Behavior, 77, 126-139.

McArdle, S., Waters, L., Briscoe, J. P., \& Hall, D. T. (2007). Employability during unemployment: Adaptability, career identity and human and social capital. Journal of Vocational Behavior, 71, 247-264.

Moreno, M. L. R. (2011). A educação para a carreira: Aplicaçóes à infância e à adolescência. In M. C. Taveira \& J. T. Silva (Eds.). Psicologia vocacional: Perspectivas para a intervenção (pp. 29-58). Coimbra: Imprensa da Universidade de Coimbra.

Morrison, R. F. \& Hall, D. T. (2002). Career adaptability. In D. T. Hall, Careers in and out of organizations (pp. 205-233). Thousand Oaks, CA: Sage.

Oliveira, A. L. (2006). Aprendizagem autodirigida: Um contributo para a qualidade do ensino superior. Dissertação de doutoramento não publicada. Coimbra: Universidade de Coimbra.

Osipow, S. H. \& Spokane, A. R. (1987). The Occupational Stress Inventory. New York: Marathon Consulting Press.

Pryor, R. G. L. \& Bright, J. E. H. (2003). The chaos theory of careers. Australian Journal of Career Development, 12, 12-20.

Quirino, I., Paixáo, M. P. \& Silva, J. T. (2010). Impacto da técnica "Job Shadowing" no desenvolvimento vocacional de estudantes do $12 .^{\circ}$ ano de escolaridade. In M. C. Taveira, A. D. Silva (Coords.), C. Lobo, J. C. Pinto, A. Araújo, S. Ferreira, L. Faria, C. Ussene, N. Loureiro, M, Königstedt, M. Carvalho \& S. Gonçalves, Desenvolvimento vocacional: Avaliação e intervenção (pp. 115-128). Braga: Associação Portuguesa para o Desenvolvimento da Carreira.

Rachman, G. (2011). O mundo de soma zero. Lisboa: Quetzal.

Rousseau, D. M. (1995). Psychological contracts in organizations. Understanding written and unwritten agreements. Thousand Oaks, CA: Sage. 
Scholl, M. B. \& Cascone, J. (2010). The Constructivist Resume: Promoting the career adaptability of graduate students in counseling programs. The Career Development Quarterly, 59, 180-189.

Silva, J. M. T. (2004). Avaliação da maturidade de carreira. In L. M. Leitão (Coord.), Avaliação psicológica em orientação escolar e profissional (pp. 263-316). Coimbra: Quarteto.

Silva, J. M. T. (2010/2011). Editorial: Apresentação do número temático dedicado à "Construçâo da vida: Um paradigma para compreender a carreira no século XXI”. Revista Portuguesa de Psicologia, 42, 9-11.

Savickas, M. L. (1997). Career adaptability: An integrative construct for life-space. Life-span theory. Career Development Quarterly, 45, 247-259.

Savickas, M. L. (2000). Renovating the psychology of careers for the twenty-first century. In A. Collin \& R. A. Young (Eds.), The future of career (pp. 53-68). Cambridge: Cambridge University Press.

Savickas, M. L. (2005). The theory and practice of career construction. In S. D. Brown \& R. W. Lent (Eds.), Career development and counseling: Putting theory and research to work (pp. 42-70). Hoboken, NJ: John Wiley \& Sons.

Savickas, M. L. (2011). Career counseling. Washington, DC: American Psychological Association.

Savickas, M. L., Nota, L., Rossier, J, Dauwalder, J. P, Duarte, M. E., Guichard, J., Soresi, S., Esbroeck, R. \& Van Vianen, A. E. M. (2009). Life designing: A paradigm for career construction in the 21st century. Journal of Vocational Behavior, 75, 239-250.

Savickas, M. L. \& Porfeli, E. J. (2011). Revision of the Career Maturity Inventory: The Adaptability Form. Journal of Career Assessment, 19, 355-374.

Spokane, A. R. \& Oliver, L.W. (1983). The outcomes of vocational intervention. In Walsh, W. B. \& Osipow, S.H. (Eds.), Handbook of Vocational Psychology (Vol. 2, pp. 99-136). Hillsdale, NJ: Erlbaum.

Stumpf, S. A., Colarelli, M. S. \& Hartman, K. (1983). Development of the career exploration survey (CES). Journal of Vocational Behavior, 29, 102-114.

Super, D. E. \& Knasel, E. G. (1981). Career development in adulthood: Some theoretical problems. British Journal of Guidance and Counselling, 9, 194-201.

Super, D. E. Thompson, A. S. \& Lindeman, R. H. (1988). Adult Career Concerns Inventory: manual for research and exploratory use in counseling. Palo Alto, CA: Consulting Psychologists Press.

Watts, A. G. (1996). Careerquake. Policy supports for self-managed careers. London: Demos.

Watts, A. G. \& Borbély-Pecze, B. T. (2010). The development of a lifelong guidance system in Hungary. International Journal of Educational and Vocational Guidance, 11, 17-28

Wijers, G. \& Meijers, F. (1996). Careers guidance in the knowledge society. British Journal of Guidance and Counselling, 24, 209-222. 
Série Documentos

Imprensa da Universidade de Coimbra

Coimbra University Press

2011

- U

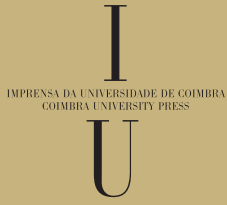

